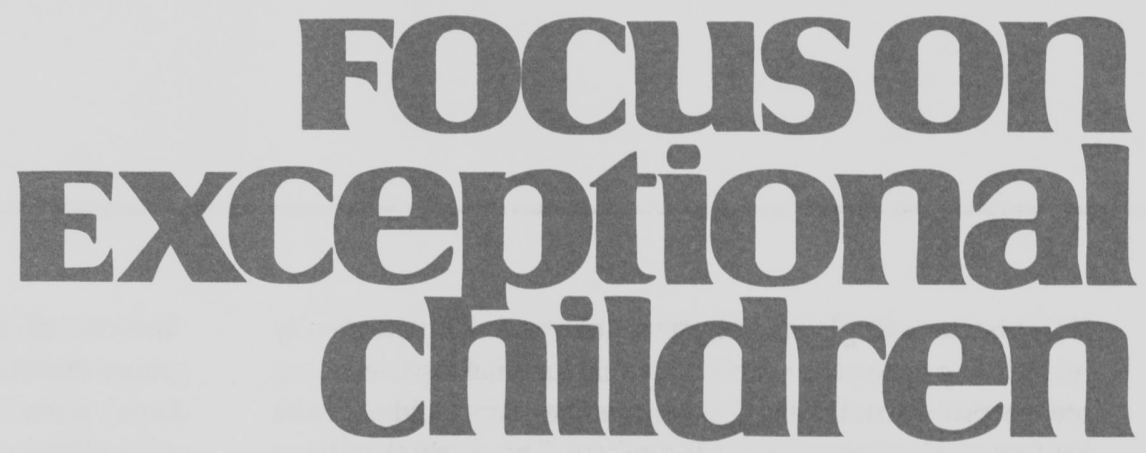

\title{
Teaching Science as Social Science: A Curriculum Focus for Adolescents with Mild Disabilities
}

\author{
Tanis Bryan and Cynthia L. Warger
}

From Benjamin Franklin and his kite to Ronald Reagan and star wars, we have had faith in science and technology to solve the serious problems that confront society. Increasingly, we have extended our belief in scientific solutions to our personal lives, where scientific studies tell us how to live longer, healthier, more beautiful lives. Thanks to science, we also now know how to evaluate our personalities to ensure more passionate love lives and greater business acumen. And, though we are not likely to be cloned in the near future, with the help of science, we can foster traits in our children that will make our ancestors proud.

But the advances we have witnessed and rely upon in science do not reside solely in the natural and physical branches. The social sciences probably are the most ubiquitous in our daily lives. Examples abound. Social science methods play a strong role in government as politicians use surveys routinely to test and to sway public opinion. Lawyers hire social scientists to help select members of a jury, as well as analyze jurors' behaviors during trials. The FBI established a social science division to develop profiles of terrorists. Businesses employ ethnographers to observe customers' buying habits - information that is used to improve merchandising strategies. Large retail stores have hired social scientists to "mine" sales data, from which to glean unique buying trends and preferences. (One store learned that disposable diapers and beer were the biggest sellers on Thursday nights.) Health-care providers have conducted studies to determine the impact of humor on health. Even movie producers sometimes conduct studies to determine the most crowd-pleasing ending for a film.

To successfully navigate a society that increasingly relies on the social sciences to influence our thinking and actions requires a strong knowledge base in the domain. Our decisions must be informed; otherwise we simply will fall prey to those who seek to garner our attention, sympathies, and dollars for profit. Moreover, we must help our children develop the knowledge and tools to cope in society. When enticing someone to buy their product, marketers do not discriminate by age. Children probably are bombarded as frequently as adults with television and radio ads to persuade them to purchase the latest products.

To ask critical questions is not enough. We also have to recognize how information might be biased in how it is presented, collected, and interpreted. The need for knowledge and analytic tools is even greater for children because of the daily pressure that confront them. They are pressured to do and not to do things such as smoke, drink alcohol, take drugs, have sex, and join gangs.

Tanis Bryan is with the College of Education, Arizona State University. Cynthia L. Warger is with Warger, Eavy, and Associates, Reston, VA. 
Doing homework, getting along with siblings, dealing with family rules, living up to parental expectations, and making friends are present problems. During these formative years children make judgments about themselves and others. These decisions have long-term implications for their lives. Like adults, children need to be aware of the various forces (for example, peers and television ads) that seek to influence their thinking and actions. They, too, need to make informed decisions.

\section{A CURRICULUM FOR UNDERSTANDING HUMAN BEHAVIOR}

Life has changed from what it was in the 1950s, when most curricula were developed. In fact, the curriculum reforms of the 1980s rarely addressed "new" skills and understandings that students need. Instead, reformers revamped the traditional academic areas by calling for inquiry-based, hands-on, problemsolving approaches to teaching basically the same content $(\mathrm{Pu}-$ gach \& Warger, 1996). Even with the call for new standards in

\section{Focuson
Exceptional
children}

ISSN 0015-511X FOCUS ON EXCEPTIONAL CHILDREN (USPS 203-360) is published monthly except June, July, and August as a service to teachers, special educators, curriculum specialists, administrators, and those concerned with the special education of exceptional children. This publication is annotated and indexed by the ERIC Clearinghouse on Handicapped and Gifted Children for publication in the monthly Current Index to Journals in Education (CIJE) and the quarterly index, Exceptional Children Education Resources (ECER). The full text of Focus on Exceptional Children is also available in the electronic versions of the Education Index. It is also available in microfilm from Xerox University Microfilms, Ann Arbor, MI. Subscription rates: Individual, \$30 per year; institutions, \$40 per year. Copyright (C) 1998, Love Publishing Company. All rights reserved. Reproduction in whole or part without written permission is prohibited. Printed in the United States of America. Periodicals postage is paid at Denver, Colorado. POSTMASTER: Send address changes to:

$$
\begin{gathered}
\text { Love Publishing Company } \\
\text { Executive and Editorial Office } \\
\text { P.O. Box } 22353 \\
\text { Denver, Colorado } 80222 \\
\text { Telephone (303) } 757-2579
\end{gathered}
$$

Edward L. Meyen

University of Kansas
Glenn A. Vergason Georgia State University
Richard J. Whelan

University of Kansas Medical Center
Stanley F. Love

Publisher
Thomas Love

Managing Editor "behavioral" studies by the major social studies and science groups (see Kendall \& Marzano, 1995, for a summary of standards), science remained locked in the study of physical and biological phenomena and social studies remained the province of history, geography, and government.

Including social science as part of elementary and secondary curricula provides children the opportunity to acquire knowledge about the science of human behavior that can be applied directly to making informed decisions in their daily lives. Social science standards include:

- Understands the processes and products of social science.

- Understands how thoughts and feelings influence human behavior.

- Understands how other people influence the individual.

- Understands how people influence each other.

These understandings enable students to generate and test alternative hypotheses about people, to explore how their feelings influence their behavior, and to test the impact of various approaches in social interactions. In addition, because the social sciences use the scientific method to investigate questions, students learn key concepts underlying all science: objectivity, reliability, and validity of measurement.

Among the benefits of including social science in the curriculum are the following:

1. Because the process of doing social science and the topics covered have widespread appeal, social science makes curriculum meaningful and relevant to students.

2. In the scientific method teachers have a nonbiased process for broaching sensitive topics (for example, drug use, racism) in ways that do not infringe upon students' privacy.

3. Children are more likely to act wisely when they are included in decision-making, and, thus, a curriculum that shows them how to test their views and ideas about themselves and others systematically is more likely to have the desired effects than adult lectures about what is "right" or "wrong."

4. Many children, especially those with learning disabilities and emotional and behavioral disorders, have social information processing deficits that tend to improve with mastery of social science concepts.

Over the years, we have been working with special and general educators to introduce social science-and thereby the principles of the scientific method-to their students using an approach called Amazing Discoveries (Bryan \& Bryan, 1995; Bryan \& Warger, 1997). This approach, developed by the lead author, has been field-tested successfully with fourth- through 10th-grade students with and without mild disabilities (e.g., 
learning disabilities, emotional-behavioral disorders) in inclusionary and self-contained elementary, middle, and secondary classrooms (Bryan \& Bryan, 1997).

In this article we describe the framework for the Amazing Discoveries approach. Using actual examples from the curriculum, we illustrate how teachers can integrate social science subject matter-content and process skills-into a stand-alone science program, as well as interdisciplinary units that include science. Because data indicate that the Amazing Discoveries approach results in knowledge and skills development for students with mild disabilities, we begin the discussion with a rationale related to this population.

\section{RATIONALE FOR EXPANDING THE CUR- RICULUM TO INCLUDE SOCIAL SCIENCES FOR STUDENTS WITH MILD DISABILITIES}

Even though social science curriculum is relevant, meaningful, and appropriate for all students, it is particularly advantageous for students with mild disabilities because:

1. Students with mild disabilities have social information processing deficits that can be addressed through a social science curriculum.

2. Students with disabilities traditionally have been denied access to science curriculum.

3. Students with mild disabilities can learn science when it is presented in a hands-on, inquiry-based format, in which students can answer questions they truly care about.

Understanding the rationale for a social science curriculum is the first step in establishing a strong foundation for implementation.

\section{Social Information-Processing Needs}

Students with mild disabilities have been shown to have deficits in social information-processing that lead to inappropriate behaviors (Bryan, 1997; Crick \& Dodge, 1994). Consider the results of the research:

- Students with emotional-behavioral disorders tend to misperceive the actions of others (Dodge, 1985; Dodge \& Newman, 1981). For example, they tend to interpret social cues negatively. Thus, when outcomes are negative (e.g., someone squirts mustard on their shirt in the lunchroom), they tend to interpret this as intentional and respond aggressively, whereas other students would be more likely to interpret the event as an accident.

- Students with emotional-behavioral disorders often show a bias in attending to aggressive rather than other cues in the environment (Dodge \& Newman, 1981; Gouze, 1987).

- Social information-processing problems demonstrated by students with emotional-behavioral disorders include lack of empathy (Ellis, 1982), inability to take a perspective different from their own (Feshbach, 1975; Spivack, Platt, \& Shure, 1976), limitations in generating prosocial solutions to interpersonal conflicts and the selection of incompetent responses to provocations (Walker, Colvin, \& Ramsey, 1995), and failure to monitor the effects their behavior has on others (Walker et al. 1995).

- Students with learning disabilities have been found to be less skillful in encoding social cues, such as labeling emotions (Tur Kaspa \& Bryan, 1994); interpreting social cues (Pearl \& Cosden, 1982); generating strategies to resolve social situations, 1987); selecting social responses that are appropriate (J. H. Bryan, Sonnefeld, \& Greenberg, 1981); and responding appropriately (Pearl, 1982).

- Students also are vulnerable in the areas of depression and loneliness (Margalit, 1994).

- The relationship between social perceptual and interpretation biases have been demonstrated in samples of children from kindergarten through eighth grade (Feldman \& Dodge, 1987; Guerra \& Slaby, 1989), among residential populations (Milich \& Dodge, 1984) and incarcerated adolescent males (Crick \& Dodge, 1994), as well as school-based groups (McClaskey, 1988).

- Only those social skills training programs that included training social cognition have produced significant positive effects (cf., Ager \& Cole, 1991; Alberg, Petry, \& Eller, 1993; Beelmann, Pfingsten, \& Losel, 1994; Izzo \& Ross, 1990).

Clearly, students with mild disabilities need assistance in developing social-processing skills. Too often the presence of these skills is assumed. Rarely do students with disabilitiesany students, for that matter-receive specific cognitive-process training that they can use to enhance their learning of academic subject matter (e.g., listening objectively; knowing when and how to ask questions). The social sciences do offer a cognitive-processing approach with the scientific method. When taught directly, students not only learn about social science concepts but also develop cognitive processes and skills that will empower them for life.

\section{ACCESS TO THE STANDARD SCIENCE CURRICULUM}

The academic curriculum is the core of general education. Special education for students with mild disabilities generally 
has emphasized helping students acquire basic skills germane to the standard curriculum. Basic skills in reading and mathematics, and not science or social studies, dominate most remedial interventions.

Actually, scant attention has been devoted to teaching any science to students with disabilities. From 1978 to 1985 only three articles on science teaching were found in six major special education journals (Lesson, Budzinski, Karch, \& Van Acker, 1989). In a study comparing the amount of time children with disabilities and their nondisabled peers receive in academic instruction, researchers found that, though the average amount of time devoted to science in general classrooms was $7.2 \%$ (Sirotnik, 1983), about $5.1 \%$ of the day was allocated to science for children with mild learning disabilities and $2.5 \%$ of the day for children with severe disabilities (Thurlow, Ysseldyke, \& Graden, 1982).

Even when students with disabilities are mainstreamed into general education classrooms, science is one of the primary times when they are sent back to resource rooms for basic skill instruction (Walsh, 1977). Historically, teachers have labeled science as too difficult and lab experiences too dangerous for students with disabilities (Walsh, 1977). Concerns about science being dangerous for students with emotional and behavioral disorders prevail to this day (Scruggs \& Mastropieri, 1995).

A social science curriculum geared to the learning characteristics of students with mild disabilities offers teachers a practical way to introduce science concepts and process skills. Because the content is concrete and meaningful to students, the chance of motivating students and sustaining their interest is greater. Furthermore, nothing is physically dangerous about social science. Indeed, one benefit to classroom teachers is that social science can be done anywhere with people, thus reducing the need for labs, complicated equipment, and expensive materials.

\section{An Activity-Oriented Approach}

As an outcome of the curriculum reform movement in science and mathematics education, teachers are shifting to an inquiry-based approach in which students participate in in-depth study of meaningful content. For example, exemplary curricula for middle school have been defined as (Aims, 1988):

- Highly creative and relate content to issues of paramount concern to preadolescent students.

- Support a reflective Socratic approach to instruction.

- Develop thinking skills.

- Present the content in a rigorous fashion.

To support this new instructional orientation, teachers have turned to an activity-oriented approach in which students engage in investigations (Champagne, Newell, \& Goodnough, 1996).
Teachers and administrators are more likely to have a positive view of curriculum modifications that are appropriate for all students than adaptations that benefit only a few students (Bryan \& Bryan, 1997). From a positive perspective, some evidence indicates that students with mild disabilities perform better in an activities-oriented curriculum than in a traditional curriculum. Bay and her colleagues (1992) found that students with learning disabilities and students with emotional-behavioral disorders performed better on a delayed test of generalization following instruction in an activities-oriented condition than students taught in direct instruction of the same content. In another study Bennett (1978) found that students with mild disabilities and physical handicaps benefited from an activities-oriented science program with adapted materials based on gains in pre-post tests. Even more surprising given the cautions raised by special educators that students with mild disabilities will "get into more trouble" in hands-on lessons (see for example, Scruggs, Mastropieri, Bakken, \& Brigham, 1993) have been the findings that students with mild disabilities actually may increase their appropriate behavior during activities-oriented science classes compared to classes taught more traditionally (MacDougall et al., 1981). Indeed, Bryan (1997) found that students with behavior problems were more on-task during handson experiments than during regular instructional activities.

Teaching social science necessitates an activities-oriented approach-hands-on experiments and demonstrations that stress the scientific processes (e.g., observing, interviewing, surveying, recording, predicting, analyzing) that are used in the systematic study of human behavior. An activities-oriented approach that focuses on the content of social science (e.g., attributions, expectancies, reinforcement, conformity) has the advantage of making learning more motivating and meaningful. Thus, social science meets the standards and goals of school district-mandated curriculum and at the same time provides teachers with a strategy for addressing the specific social information-processing deficits of students with mild disabilities.

\section{The Amazing Discoveries Framework}

The Amazing Discoveries framework forges a connection between learning how to do science and learning about human behavior. The social sciences are used as a means to teach the basic principles underlying the procedures that all scientists use. The essence of science is not to collect facts; rather, science is a set of procedures and methods that enable individuals to advance knowledge about the world. Several basic concepts are fundamental to doing social science research:

- Objectivity in measurement

- Validity of measurement

- Reliability of measurement 
In the Amazing Discoveries framework, students study these concepts in-depth to provide a basis for the hands-on activities, students are introduced to measurement techniques that are used to study human behavior. These include:

- Observations

- Experiments

- Interviews

- Surveys

The Amazing Discoveries framework is designed as a two- . prong process: In each activity students learn something about the process of social science and something about human behavior. Students learn about the social science constructs and then apply their knowledge as researchers. Depending on the teacher's purpose, the Amazing Discoveries demonstrations and experiments can serve as either a stimulus to learn social science content ("what makes people "tick") or as a means for developing and applying research skills (e.g., constructing and administering surveys).

In the first phase, teachers use hands-on demonstrations and experiments to teach students social science processes (why and how social scientists use measures that are objective, reliable, and valid). In the next phase, the roles are shifted and students become the researchers. They conduct experiments with others - students in other classes, family, friends, neighbors. This second phase of engaging students in the research process often results in students deepening their understanding of the social science construct while applying their knowledge of the process of doing research. Students begin to generate their own hypotheses and design new experiments to test their assumptions regarding how other people think, feel, and act (e.g., expectancies, conformity).

\section{Science as a Way of Thinking}

Scientific thinking can and should be nourished in children. The Amazing Discoveries framework emphasizes thinking skills (e.g., analytic, critical, creative, original, synthesizing, making predictions, drawing inferences). What's more, the program nests social cognitive instruction in a science curriculum. Engaging all students, including those with mild disabilities, in social science experiments increases their knowledge and understanding of how social sciences can influence the things they care most about in their daily lives. This approach also provides them with methods that enable them to take action and be informed consumers and citizens. As students do social science experiments, they fine-tune and develop social information-processing strategies-strategies that students with mild disabilities typically lack. We have observed that when students with mild disabilities are confronted with evidence that goes counter to their preconceived (and often faulty) notions about people, they believe their data, sometimes with dramatic changes in their beliefs and behavior.

\section{The Amazing Discoveries Curriculum}

Amazing Discoveries offers a fun and innovative way to bring social science research and methodology and concepts into the classroom. The program includes 28 hands-on experiments and demonstrations that teach the principles and processes involved in doing social science. The lessons in the Amazing Discoveries program have been field-tested with fourth- through 10th-grade students, some of whom were receiving special education services for emotional-behavioral disorders or learning disabilities. The curriculum has been implemented successfully in inclusionary and self-contained elementary, middle, and secondary classrooms (Bryan \& Bryan, 1996).

The Amazing Discoveries program is consistent with current curriculum standards in science, math, and social studies, as it emphasizes problem solving, critical thinking, and interdisciplinary study. Because science rarely is conducted in isolation, Amazing Discoveries adds to interdisciplinary learning. Key connections include (Bryan \& Warger, 1997):

- Social studies: Building background knowledge (understanding one's place in society), developing citizenship skills, using social science research tools (e.g., observations, interviews, surveys).

- Science: Using the scientific method to understand human behavior, thinking scientifically (e.g., forming and testing hypotheses), using science research tools (e.g., experiments).

- Language arts: Communicating with different audiences, asking good questions, presenting findings, persuading others.

- Mathematics: Solving problems, manipulating and portraying data, drawing inferences and conclusions.

The Amazing Discoveries experiments and demonstrations are organized around four themes:

1. Basic principles in doing science (e.g., objectivity, reliability, validity).

2. How thinking influences our behavior (e.g., expectancies, attributions, intentionality, assumptions, moods).

3. How other people influence our behavior (e.g., conformity, peer pressure, social reinforcement, physical attributes).

4. How people influence each other as they interact (e.g., social reinforcement, nonverbal behavior, matching communication style to age of partner). 
Each section contains a series of lessons designed around a demonstration or experiment. Lessons are presented in a cookbook fashion. Each lesson includes the topic, purpose, lesson overview, procedures, supporting activities to reinforce the concept (i.e., crossword puzzle, word search), quiz, suggestions for applying the program to other content areas, and suggestions for discussions and follow-up activities. Because most teachers have not had many courses in science or psychology, each experiment provides background information to help teachers feel comfortable presenting the topic to their students. A separate student section includes background information and a description of the experiment.

\section{Sample Experiments}

Examples of experiments in each of the four Amazing Discoveries Units follow. Each example includes suggestions for integrating the experiment with standard curriculum, and for helping students see the applicability to their daily lives.

\section{Unit 1: Basic Principles in Science}

The first theme, Basic Principles in Doing Science, introduces students to the scientific method: formulating a hypothesis, defining, manipulating and measuring variables, interpreting and writing up the results. Science differs from other ways of gathering information in that it requires scientists to adhere to a set of criteria that eliminate the data collector's influence from the results. In this way, no matter who conducts the experiment, the results should be the same. The scientific method helps us to sort out facts from opinions and beliefs.

We have to be explicit in applying the principles of science in social science because people-the target of social sciences - are inexact measures. Thus, special care has to be taken to ensure that social science experiments meet scientific standards. Through participating in a series of experiments and demonstrations, students explore a variety of factors critical to social sciences. The experiments and demonstrations in Unit 1 focus on:

- How the scientific method helps us distinguish between our opinion and others' opinions.

- How the fallibility of human senses can bias the results of an experiment.

- Why getting reliable (consistent) and valid (true) results in measurement is difficult.

- How interpretations of events differ, even when we see the same thing.

- How different ways of phrasing questions change responses.
- How bias in selecting people to survey can influence results.

- Why we collect different kinds of measures to verify what people say.

Because students will not have had any experience doing social science experiments, we engage them in a number of activities to acclimate them. Suggestions for introducing social science to students include the following activities.

Getting Started. Most students define social science as "doing science with your friends" (Bryan \& Bryan, 1996). The first step in doing social science experiments is to help students understand that social science is the scientific study of human behavior. Students define social science and what they know about social science. They learn that social science is the scientific study of people - the way people think, feel, and act. Students are introduced to the influence of social science in their daily lives using various activities. Here are some examples.

- Students generate a list, or web, of people who do social science, and places where social science is done. Students discuss how social scientists work with businesses (e.g., testing the effectiveness of television advertising), politicians (e.g., predicting election results), and educators (e.g., developing standardized tests) to apply social science methods to understand and influence their thinking and behavior.

- Students generate a list of ways in which people try to influence their thinking and behavior, and their parents' thinking and behavior. Students work in small groups to generate issues of importance to them, their families, or the school that they think would be interesting to know more about.

- Students start a portfolio in which they record the issues identified as important in their small groups, keep track of new concepts and vocabulary, and their science logs (see Figure 1). As students acquire knowledge and skills in applying scientific methods to studying human behavior, they can return to their portfolios and use the results of discussions and experiments to generate their own experiments.

Example of Experiment in Unit 1: Can You Trust Your Eyes? To orient students to social science, they are introduced to three basic principles that govern all sciences_objectivity, reliability, and validity of measurement - and are shown how these principles apply to the scientific study of human behavior. In Example 1 students learn the objectivity principle, which dictates that scientists cannot trust their senses. For instance, the world may look flat, but it isn't. A glass may look empty, but it 


\begin{tabular}{l} 
1. Hypothesis \\
\hline 2. Measurement \\
\hline 3. Analysis and Results \\
\hline 4. Interpretation and Discussion \\
\hline Figure 1 \\
\hline Q. Application \\
\hline \\
\hline
\end{tabular}

isn't. Students need to learn the fallibility of human judgment that results from limitations in human senses.

In this Amazing Discoveries demonstration, students learn the principle of objectivity through a visual illusion demonstration in which they experience how their eyes can deceive them. Figure 2 presents an outline of the lesson that demonstrates why we cannot trust our eyes, and the Müller-Lyer visual illusion.

Students indicate whether Line A is longer, shorter, or the same as line B. People typically say that line B is longer, even though $A$ and $B$ really are of equal length. The explanation for the illusion is that the arrowheads provide false distance cues; as a result, we err in estimating the distance between the line segments.

Extensions. The concept of illusions can be extended to other content areas. In Social Studies, students can identify illusions that influenced history, or listen to "War of the Worlds" to ex-

\begin{tabular}{|c|c|c|c|}
\hline Key Vocabulary & Materials & $\begin{array}{l}\text { Science } \\
\text { Processes }\end{array}$ & Math Skills \\
\hline Data & $\begin{array}{l}\text { Müller-Lyer } \\
\text { Illusion }\end{array}$ & Measure & Tally results \\
\hline Objectivity & $\begin{array}{l}\text { Student } \\
\text { response }\end{array}$ & Record data & $\begin{array}{l}\text { Find } \\
\text { percentages }\end{array}$ \\
\hline Scientific method & Sheet of paper & Interpret data & $\begin{array}{l}\text { Graph } \\
\text { and chart } \\
\text { results }\end{array}$ \\
\hline Social science & Rulers & & \\
\hline Generalize & Graph paper & & \\
\hline \multicolumn{4}{|c|}{$\begin{array}{l}\text { Procedure } \\
\text { 1. Students respond to Müller-Lyer visual illusion and record on } \\
\text { their data sheets whether they believe line A is longer, line B } \\
\text { is longer, or lines } A \text { and } B \text { are the same. } \\
\text { 2. Students tally the number of students who saw line A as } \\
\text { longer, line B as longer, or lines A and B as the same length. } \\
\text { 3. Students graph the results of the tally. } \\
\text { 4. Students administer the Müller-Lyer visual illusion to others } \\
\text { outside their class and bring back their data for classroom } \\
\text { tallying and graphing. } \\
\text { 5. Students examine other visual illusions to learn how their } \\
\text { perceptual sets influence their interpretation of illusions. } \\
\text { 6. Students discuss the outcomes, consider alternative interpre- } \\
\text { tations of their data, examine other visual illusions (e.g., } \\
\text { movies, advertising), and generate examples of other illusions } \\
\text { used to fool people. }\end{array}$} \\
\hline
\end{tabular}

tend the concept to "can't trust what you hear." In Language Arts, students read fables containing references to illusions (e.g., "The Wolf in Sheep's Clothing"). Or teachers might expand the lesson to focus on critical media viewing skills.

For example, the advertising industry is notorious for creating illusions that help sell their products. Students can generate examples of how they were fooled, or not fooled, by television advertisements. In Science, students can examine how various creatures create illusions to protect themselves or attract food. Students can experiment with making illusions in which the angles of the lines are manipulated to test the limits of the Müller-Lyer illusion as a function of different angles. Students also can make their own visual illusion and administer 
it to other students, or to their parents. Students write up the results of their work using the Science Log.

Application to Social Cognitive Processing. The visual illusion demonstrates that scientists have to develop objective measures, which means that they are not influenced by the scientist's personal attributes. Using scientists as an example, the discussion is extended to the illusions as they arise in interpersonal relationships. We all have had experiences in which our senses misled us, which resulted in errors interpreting other people's behavior. These misperceptions can result in our misinterpreting other people's behavior.

Students can generate examples of when they misperceived others' behavior, or when others misperceived their behavior. Because students with mild disabilities tend to misperceive social situations (Bryan, 1997, Crick \& Dodge, 1994), the teacher can use visual illusions as a springboard to broach the topic of withholding judgments about something we have seen or heard until we can check it out, get more information, determine other people's perspectives. In a nonthreatening, impersonal way, students see for themselves why we should not assume that our interpretations of things seen or heard are correct.

\section{Unit 2: The Influence of Thoughts and Feelings on Behavior}

The demonstrations and experiments in this theme focus on how our thoughts and feelings influence our behavior. Through participating in a series of experiments, students explore a variety of internal factors that influence their behavior. The experiments focus on

- The influence of expectancies on judgments.

- Students' attributions about the causes of their successes and failures.

- Students' attributions about other persons' intentions.

- Students' inferences when information is ambiguous.

- Separating what is known from what is not known about a situation (i.e., egocentrism).

- The influence of positive affect on performance.

Each experiment makes the point that the way we think and feel has a significant influence on what we do, even though we may be unaware that this is happening.

Example of Experiment in Unit 2: What You Expect Is What You Get. Abundant evidence shows that when people expect things to happen, they often do. Somehow people's expectancies affect how they act, which guarantees that their expectations will be realized.

The rationale for being concerned about the impact of expectancies on outcomes - and its relevance to special educa- tion - is well illustrated in a study by Larrabee and Kleinsasser (1967). This study demonstrated that children obtained significantly higher scores (7.5 points) on the Wechsler Intelligence Scale when the examiner had been told that the child was of above-average intelligence than when told the child was of below-average intelligence. Other studies have showed how teachers' expectancies influence their behavior toward children, with subsequent effects on children. The influence of expectancies has been studied extensively in research on attributions, the relationship between people's beliefs about causality and outcomes.

Social scientists have had to develop methods to ensure that their expectations do not influence the outcomes of an experiment. In this experiment students learn about how expectancies can influence behavior in a study of people's ratings of a baby's intelligence. Figure 3 presents a summary of the procedures used in this experiment. After reading a description of a baby as likely to be very smart, or not likely to be very smart, students ask others to rate how smart they think the baby is likely to be. Students bring the ratings back to class and tally the ratings the two babies received.

In terms of science, students learn that if you change a variable (such as baby's IQ), you change the outcome (others ratings of the baby's IQ). Socially, students observe how their expectancies regarding the baby's intelligence influenced others' ratings of the baby.

Sometimes the results of this experiment do not confirm the hypothesis, and the not-so-smart baby gets higher ratings than the smart baby. No matter-the results will generate great discussions about judgments of intelligence and about how one person's behavior can influence another's person's behavior, even unwittingly. Students can generate instances in which their expectancies influenced their behavior, and when other people's expectancies regarding them influenced outcomes.

Extensions. In language arts, students might write a report on their expectancies for the year. To orchestrate this activity, the teacher has students break the report into sections for each content area. The teacher also can have students include the reasons why each subject is easy or hard. Students then can brainstorm ways to reduce the impact of factors they identify as making the work hard and capitalize on factors that make it easy. (Note: This activity lends itself well to having students delineate study skills.)

In social studies, students learn about events such as the stock market crash of 1929 and the widespread panic that the banks would fail. In other historical events, too, people's expectancies have had a major influence on their behavior with a subsequent impact on the entire country. In math, students analyze the results of the study, computing the mean, mode, and median. Students also can divide their data based on respondents' ages and gender. Students are particularly interested in differences be- 


$\begin{array}{llll}\text { Key Vocabulary } & \text { Materials } & \begin{array}{l}\text { Science } \\ \text { Processes }\end{array} & \text { Math Skills } \\ \text { Expectancies } & \text { Baby photo } & \text { Interview people } & \text { Tally } \\ \text { Experiment } & \text { Instructions } & \text { Collect data } & \text { Collate data } \\ \text { Hypothesis } & \text { Rating sheet } & \text { Analyze data } & \begin{array}{l}\text { Compute } \\ \text { mean, mode } \\ \text { median }\end{array} \\ \text { Subject } & \text { Data sheet } & \text { Interpret data } & \\ \text { Ethics } & & \begin{array}{l}\text { Write science } \\ \text { report }\end{array} & \text { Graph results }\end{array}$

\section{Procedure}

1. Each student is given an envelope containing the materials necessary to conduct the study: a baby photo, a description of the baby, and a rating form used to interview others about the baby's intelligence. Half the students read a description of the baby as likely to be very intelligent, half a description of the baby as not likely to be very intelligent.

2. Students are told to read the information in their envelope without consulting other students in the class, and then to interview two to four others (students in other classrooms, parents, siblings, other teachers) using the rating sheet in the envelope.

3. Students role-play how to approach people to ask them to fill out a form so they feel comfortable with the assignment.

4. Students discuss the ethics of conducting research with others (subjects' answers are confidential, and the interviewer should stop if subjects are uncomfortable with the question).

5. Students bring their record sheets back to class for analysis.

6. Students divide into groups based on which condition they are in (intelligent versus not intelligent baby), tally the ratings, compute the mean, mode, and median (depending on their level of math skills), and graph the data.

7. Students discuss the results, review the vocabulary, and complete the Science Log.

\section{Figure 3}

\section{What You Expect is What You Get}

tween boys and girls. This discussion can be extended to consider whether boys and girls have different expectancies in school and elsewhere. For instance, much data indicate that American girls have low math expectancies and high math anxiety compared to American boys and girls born in other countries. Students can examine whether this is true in their class.

Application to Social Cognitive Processing. This experiment demonstrates how students' expectations regarding a baby's intelligence influences the ratings other people give the baby. At first blush this concept may seem too abstract for students with mild disabilities. We have found, however, that when students see the two identical baby pictures alongside the two different descriptions of each baby's intelligence, they understand the scientific principle: When you change a variable (i.e., the baby's descriptions), you change the outcome. They also can talk about how the two babies came to be rated differently. Why did they elicit different responses?

\section{Unit 3: Social Influences}

The experiments in this theme focus on how other people influence our behavior. By participating in a series of experiments and demonstrations, students explore a variety of factors external to ourselves that influence our beliefs, judgments, and behaviors. The experiments focus on:

- The influence of physical appearance on people's judgments and responses.

- Factors that influence conformity (e.g., age, gender).

- Factors that influence judgments of victims (the "just world" hypothesis) and notions about justice and fairness.

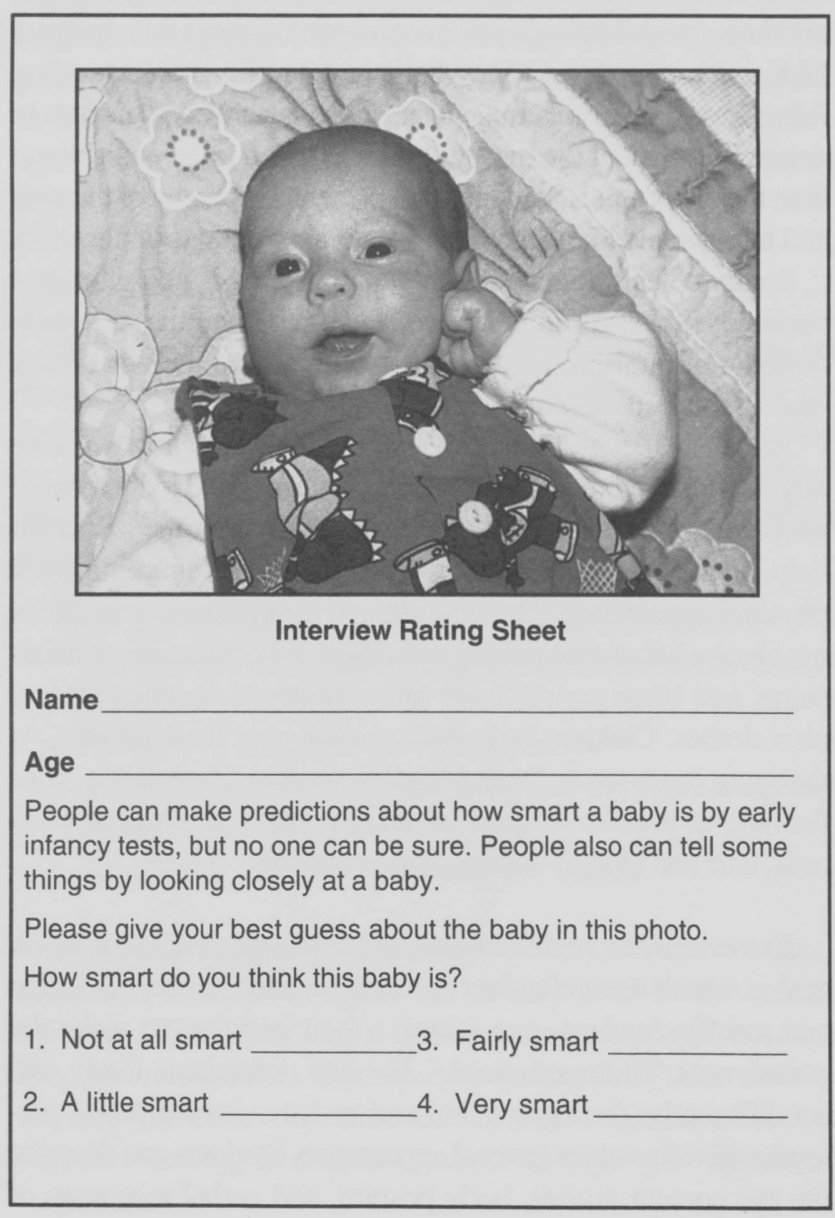


- The influence of role models on prosocial behavior.

- Face-saving ways to say "no."

- Adjustments in communication style that are responsive to characteristics of different audiences (e.g., age, relationship, reason for communication).

\section{Example of Experiment in Unit 3: Fitting the Punishment to} the "Criminal". Physical appearance is very important in American culture. Parents recognize the importance of physical appearance as they struggle to get their children to dress neatly and comb their hair. Children also recognize the importance of physical appearance. They use it to make a statement about their independence from their parents, as well as their social affiliations. Wearing outlandish hairstyles and clothes can be a harmless form of teenage rebellion. Carried to its extreme, gang membership is marked by clothing styles, colors, and haircuts.

In this experiment, students examine how physical appearance influences the amount of punishment an individual might receive. Half the students in the class are given a photo of a child who is smiling and dressed neatly; half are given a photo of a child who is frowning and dressed messily. Both groups are told how the child disobeyed her parents. Students then indicate how much punishment they believe the child should receive. After completing the rating sheet, students analyze their data to determine whether the messy child was given more punishment than the clean child. Students also present the photos of the neat and messy child to others and obtain others' ratings of the child.

Students learn the scientific principle that if you change a variable (physical appearance), you change the outcome (amount of punishment). Figure 4 summarizes the procedures used in this experiment.

After analyzing their results, students discuss how we take physical appearances into account when we make judgments of people (e.g., who we want for friends, who we trust to ask for help or advice), and choices students make regarding their physical appearance. The experiment demonstrates that life is not always fair. Some people are judged to be beautiful or handsome, and some people have more money than others to buy nice clothes. Children have little control over these factors. At the same time, we do have a certain amount of control in conforming to popular notions of attractiveness in terms of neatness, hair and clothes styling, and grooming.

Extensions. In social studies, students can conduct a mock trial in which one defendant is clean-cut and the other is sullen and scruffy. Students can examine their impulses to make the punishment "fit the criminal." The two defendants likely will act differently; their nonverbal and verbal communication patterns will reflect their general appearance. Students can describe the eye contact, smiles, body posture, and verbal responses of

Key Vocabulary Materials $\quad \begin{aligned} & \text { Science } \\ & \text { Processes }\end{aligned}$
Physical appearance Drawings of $\quad \begin{aligned} & \text { Conduct } \\ & \text { experiment }\end{aligned}$
Hypothesis $\quad$ Mesponses
$\quad$ child and neat
Analyze data

the two defendants. Students also can have a mock election in which messy and clean children are candidates for school offices. Which candidate would students vote for? Students also can examine how people use physical attributes to express their personal beliefs about politics.

In language arts, students can write a story in which they make predictions of what the clean and messy girls will do when they grow up. Students discuss the differences in the futures they predict based on the physical appearances of the two children.

Application to Social Cognitive Processing. Two topics are called into play in this experiment. One has to do with the influence of physical appearance on social relationships. The second has to do with punishment. The topic of physical appear- 


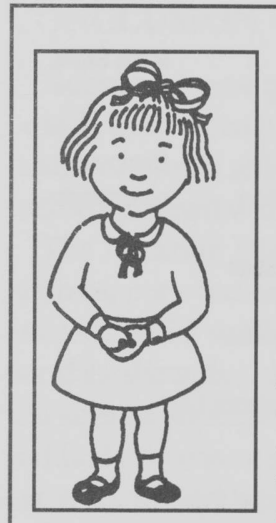

\section{Social Science-Student Survey}

This is a drawing of Claudia, a 3-year old girl who lives with her parents and older brother in Mesa, Arizona. This drawing was made last summer when she was visiting her aunt in Chicago. Claudia likes to play with her dog, Morgan, and in the summer she goes swimming in the local pool.

Claudia's parents told her not to touch the cookies her Mom had bought for dinner. Claudia disobeyed her parents. She grabbed two cookies and ate them even though her parents were watching. Her parents were angry and decided to punish her by making her stay in her room. If you were Claudia's parent, how long would you make her stay alone in her room?

Mark how long Claudia should be made to stay in her room.

0 minutes

5 minutes

10 minutes

15 minutes

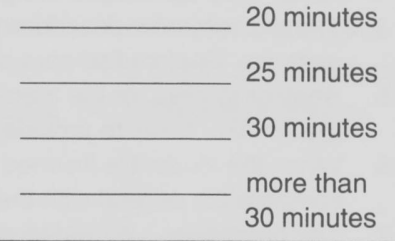

\section{Social Science-Student Survey}

This is a drawing of Claudia, a 3-year old girl who lives with her parents and older brother in Mesa, Arizona. This drawing was made last summer when she was visiting her aunt in Chicago. Claudia likes to play with her dog, Morgan, and in the summer she goes swimming in the local pool.

Claudia's parents told her not to touch the cookies her Mom had bought for dinner. Claudia disobeyed her parents. She grabbed two cookies and ate them even though her parents were watching. Her parents were angry and decided to punish her by making her stay in her room. If you were Claudia's parent, how long would you make her stay alone in her room?

Mark how long Claudia should be made to stay in her room.

$$
\begin{array}{lr}
0 \text { minutes } & 20 \text { minutes } \\
5 \text { minutes } & 25 \text { minutes } \\
10 \text { minutes } & 30 \text { minutes } \\
15 \text { minutes } & \text { more than } \\
& 30 \text { minutes }
\end{array}
$$

ance, the connection between clothing, hairstyles, and judgments, and peers' versus adults' judgments is an important one for all students, especially those with mild disabilities.
For example, students who are involved in the judicial system need to understand how their physical appearance (and nonverbal behavior) can influence police officers, parole officers, and judges. Adolescents looking ahead to having jobs need to understand how their appearance may influence getting and keeping a job. The need to make distinctions between conforming to adolescent fads and adult standards can be discussed as part of this experiment. Because the discussion takes place in the context of analyzing the results of an experiment, teachers and students can discuss preferences and responses to different styles, drawing attention to the importance of this issue without pointing fingers at any particular student.

Regarding punishment, students who have had difficulty over the years with authority have strong feelings and beliefs about what is fair and just. They usually have much to 'say on this issue, and their observations often are on target. For example, one self-contained classroom of students with emotional and behavioral disorders relied on a behavior modification token system. A number of students believed that the system was not fair because teachers showered bonus points on students when they returned from being suspended and students who behaved did not receive bonus points. The students developed a survey about the point system and administered it to other students and teachers in the school. The results of their survey found that teachers agreed that the misbehaving students were given more bonus points, but other students liked the point system.

\section{Unit 4: Social Communication}

The experiments and demonstrations in this theme focus on the roles of verbal and nonverbal behaviors in the course of social interactions. In these demonstrations students are made aware of the role of nonverbal language in controlling the flow of social interactions. In different demonstrations their attention to nonverbal communication is addressed by:

- Examining how pupil dilation reveals our feelings.

- Examining the impact of social reinforcement (i.e., saying "uh huh").

- Delivering bad news in different ways.

- Assessing the impact of positive moods on prosocial behavior.

- Identifying strategies for being persuasive.

Example: What Listeners Need to Know. When we communicate, we have to figure out exactly what listeners need to know. Listeners can misunderstand messages because speakers fail to provide adequate information. In this activity a referential communication task demonstrates the effects of listeners' asking questions upon the adequacy of speakers' responses. 
In the first of two trials, a student volunteer describes a picture to the class. Classmates draw it without being allowed to see the picture or ask questions about it. In the second trial a student describes a second picture, but classmates can ask questions. Students measure the length of time to task completion and the accuracy of picture reproduction under the two conditions. Figure 5 summarizes the lesson.

Extension. The hypothesis of this study is that students will produce the pictograms faster when they cannot ask questions, but that their reproductions will be more accurate when they can ask questions. In social studies, students can examine the ramifications of speed and efficiency versus effectiveness. This issue has become increasingly important in the industrial age. Modern-day businesses aim for both efficiency and effectiveness, and students can discuss the extent to which contemporary businesses are successful in achieving both goals. In language arts, students discuss asking questions from the standpoint of being a listener and a speaker. What clues do listeners give speakers to indicate they are not getting the message? How do speakers monitor the adequacy of their messages?

Application to Social Cognitive Processing. This demonstration touches upon a major problem for many students with mild disabilities. Many have problems recognizing when others have given them inadequate messages, and monitoring the adequacy of their messages to others. This is particularly difficult in classrooms when the request must be made of an adult, and when surrounded by many other students. Asking for clarification in the classroom means revealing that you do not know something that everyone else might know already. In this situation most students prefer to act like they understand and hope that someone else will ask the question. At home, on the job, with friends, giving adequate messages and asking for clarification are important. Students need to have multiple experiences and opportunities to practice evaluating messages and constructing adequate messages.

In addition, students with mild disabilities tend to do poorly on tasks that assess skillfulness in providing clear, complete messages. They tend to be less capable in sending good messages, as well as in responding adequately to messages. These students often are not good listeners, either because they fail to recognize that the message was inadequate or because they do not respond by asking for clarification, additional information, or missing information. Through participation and discussion, students can learn new strategies for improving their performance.

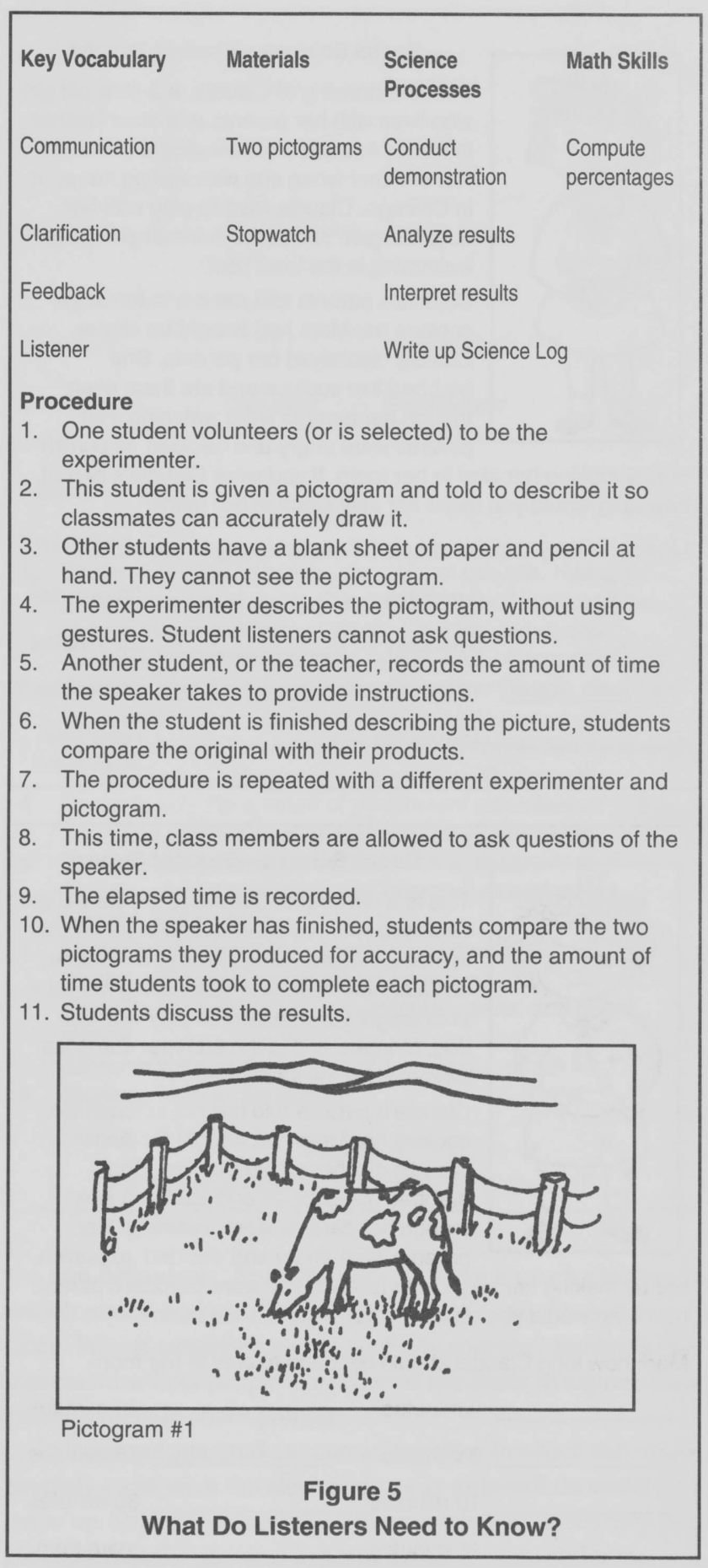




\section{CONCLUSION}

Adopting a new program or expanding an instructional approach, even when it meets the needs of general and special education students alike, is not always easy. The task, however, can be lightened with the promise of positive outcomes.

The Amazing Discoveries framework and curriculum program supports and enhances current standards in science, mathematics, social studies, and language arts curricula. Moreover, our data show that students with mild disabilities learn the social science principles, show greater levels of on-task behavior, and find the content meaningful and the experiments fun. From our work in developing, implementing, and evaluating Amazing Discoveries, we have learned that capturing the interest and attention of students, including those with mild disabilities, is possible. Moreover, by participating in Amazing Discoveries, students with disabilities have been able to learn and do science. They have successfully developed their own ideas and questions about human behavior into surveys or experiments, tested their hypotheses, analyzed their data, and drawn conclusions.

\section{REFERENCES}

Ager, C., \& Cole, C. (1991). A review of cognitive-behavior interventions for children and adolescents with behavioral disorders. Behavioral Disorders, 16, 276-287.

Alberg, J., Petry, C., \& Eller, S. (1993). The social skills planning guide. Research Triangle Park, NC: Research Triangle Institute.

Bay, M., Staver, J. R., Bryan, T., \& Hale, J. B. (1992). Science instruction for the mildly handicapped: Direct instruction versus discovery teaching. Journal of Research in Science Teaching, 29, 555-570.

Beelmann, A., Pfingsten, U., \& Losel, F. (1994). Effects of training social competence in children: A meta-analysis of recent evaluation studies. Journal of Clinical Child Psychology, 23, 260-271.

Bennett, L. M. (1978). Science and special students, Science and Children, 15, 12-14.

Bryan, J. H., Sonnefeld, J., \& Greenberg, F. (1981). Children's and parent's views about ingratiation tactics. Learning Disability Quarterly, 4, 170-179.

Bryan, T. (1998). Social problems and learning disabilities. In B. Y. L. Wong (ed.), Learning about learning disabilities. Academic Press, 2nd Edition.

Bryan, T., \& Bryan, J. (1995). Amazing Discoveries: The Social Sciences Curriculum. Foundations for Exceptional Innovations, 1648 Bennington Hollow Lane, Reston, VA 20194.

Bryan, T., \& Bryan, J. (1997). A curriculum approach to teaching social information processing: Amazing Discoveries. Learning Disabilities: A Multidisciplinary Journal, 8, 133-143.

Ellis, P. L. (1982). Empathy: A factor in antisocial behavior. Journal of Abnormal Child Psychology, 10, 123-134.
Champagne, A. B., Newell, S. T., \& Goodnough, J. M. (1996). Trends in science education (pp. 23-41). In M. C. Pugach \& C. L. Warger (Eds.), Curriculum trends, special education, and reform: Refocusing the conversation. New York: Teachers College Press.

Crick, N. R., \& Dodge, K. A. (1994). A review and reformulation of social information-processing mechanisms in children's social adjustment. Psychological Bulletin, 115(1), 74-101.

Dodge, K. A.(1985). Attributional bias in aggressive children. In P. D. Kendall (Ed.), Advances in cognitive-behavioral research and therapy, Vol. 4, 221-230.

Dodge, K. A. (1986). A social information processing model of social competence in children. In M. Perlmutter (Ed.), Cognitive perspective on children's social and behavioral development: The Minnesota symposia on child psychology, 18, pp. 77-125. Hillsdale, NJ: Lawrence Erlbaum Associates.

Dodge, K. A., \& Coie, J. D. (1987). Social information-processing factors in reactive and proactive aggression in children's playgroups. Journal of Personality \& Social Psychology, 53, 11461158.

Dodge, K. A., \& Feldman, E. (1990). Issues in social cognition and sociometric status. In S. R. Asher \& J. D. Coie (Eds.), Peer rejection in childhood (pp. 119-155). Cambridge, England: Cambridge University Press.

Dodge, K. A., \& Newman, J. P. (1981). Biased decision making processes in aggressive boys. Journal of Abnormal Psychology, 90, 375-379.

Dodge, K. A., \& Tomlin, A. M. (1987). Utilization of self-schemas as a mechanism of interpretational bias in aggressive children. Social Cognition, 5, 280-300.

Feldman, E., \& Dodge, K. A. (1987). Social information processing and sociometric status: Sex, age, and situational effects. Journal of Abnormal Child Psychology, 15, 211-227.

Feshbach, S. (1975). Empathy in children: Some theoretical and empirical considerations. Consulting Psychologist, 5, 25-30.

Goldberg, H., \& Wagreich, P. (1988). Scientists in the classroom: TIMS. University of Illinois at Chicago, Chicago, IL.

Gouze, K. R. (1987). Attention and social problem solving as correlates of aggression in preschool males. Journal of Abnormal Child Psychology, 15, 181-197.

Guerra, N. G., \& Slaby, R. G. (1989). Evaluative factors in social problem solving by aggressive boys. Journal of Abnormal Child Psychology, 17, 277-289.

Holder, H. B., and Kirkpatrick, S. W. (1991). Interpretation of emotion from facial expressions in children with and without learning disabilities. Journal of Learning Disabilities, 24, 170-177.

Izzo, R. L., \& Ross, R. (1990). Meta-analysis of rehabilitation programs for juvenile delinquents. Criminal Justice \& Behavior, 17, 134-142.

Kendall, J. S., \& Marzano, R. J. (1995). Content knowledge. Aurora, CO: McRjEL.

Larrabee, L. L., \& Kleinsasser, L. L. (1967). The effect of experimenter bias on WISC performance. Unpublished paper. St. Louis: Psychological Associates. 
MacDougall, A., Schnur, R., Berger, C., \& Vernon, D. (1981). The use of activity-centered science activities to facilitate the mainstreaming of elementary school children with special needs. Science Education, 65, 467-475.

Mastropieri, M. A., Jenkins, V., \& Scruggs, T. E. (1988). Academic and intellectual characteristics of behaviorally disordered children and youth. In R. B. Rutherford, Jr. (Ed.), Monograph in behavioral disorders: Severe behavior disorders of children and youth, 8 (pp. 86-104). Reston, VA: Council for Children with Behavioral Disorders.

McClaskey, C. L. (1988). Symptoms of ADHD, ADD, and aggression in children: Teacher ratings, peer sociometrics, and judgments of hypothetical behavior. Unpublished doctoral dissertation, Indiana University.

Milich, R., \& Dodge, K. A. (1984). Social information processing patterns in child psychiatric populations. Journal of Abnormal Child Psychology, 12, 171-189.

Nasby, W., Hayden, B., \& DePaulo, B. M. (1979). Attributional bias among aggressive boys to interpret unambiguous social stimuli as displays of hostility. Journal of Abnormal Psychology, 89, 459-468.

Pearl, R. (1982). Learning disabled children's attributions for success and failure: A replication with a labeled learning disabled sample. Learning Disability Quarterly, 173-176.

Pearl, R., \& Cosden, M. (1982). Sizing up a situation: LD children's understanding of social interactions. Learning Disability Quarterly, 5, 371-373.

Pugach, M. C., \& Warger, C. L. (1996). Treating curriculum as a target of reform: Can special and general education learn from each other? (pp. 1-22). Curriculum trends, special education, and reform: Refocusing the conversation. New York: Teachers College Press.

Ross, R. R., \& Fabiano, E. A. (1985). Time to think: A cognitive model of delinquency prevention and offender rehabilitation. Johnson City, TN: Institute of Social Sciences and Arts.

Scruggs, T. E., \& Mastropieri, M. A. (1995). Science education for students with behavior disorders. Education and Treatment of Children, 18, 322-334.

Scruggs, T. E., Mastropieri, M. A., Bakken, J. P., \& Brigham, F. (1993). Reading versus doing: The relative effects of text- book-based and inquiry-oriented approaches to science learning in special education classrooms. Journal of Special Education, 27, 1-15.

Scruggs, T. E., Mastropieri, M. A., \& Veit, D. (1986). The effects of coaching on the standardized test performance of learning disabled and behaviorally disordered students. Remedial \& Special Education, 7, 37-41.

Sirotnik, K. A. (1983). What you see is what you get: Consistency, persistency, and mediocrity in classrooms. Harvard Educational Review, 53, 16-31.

Slaby, R. G., \& Guerra, N. G. (1988). Cognitive mediators of aggression in adolescent offenders: 1. Assessment. Developmental Psychology, 24, 580-588.

Smith, S. W., \& Simpson, R. L. (1989). An analysis of individualized education programs for students with behavioral disorders. Behavioral Disorders, 14, 107-116.

Spivack, G., Platt, J. J., \& Shure, M. B. (1976). The problem-solving approach to adjustment: A guide to research and intervention. San Francisco: Jossey-Bass.

Steinberg, Z., \& Knitzer, J. (1992). Classrooms for emotionally and behaviorally disturbed students: Facing the challenge. Behavioral Disorders, 17, 145-156.

Thurlow, M. L., Ysseldyke, Y. E., \& Graden, J. L. (1982). LD students active academic responding in regular and resource classrooms. University of Minnesota: IRLD, No. 90.

Tur-Kaspa, H., \& Bryan, T. (1994). Social information processing of students with learning disabilities. Learning Disabilities Research and Practice, 9, 12-23.

Vaughn, S. (1991). Social skills enhancement in students with learning disabilities. In B. Y. L. Wong (Ed.), Learning about learning disabilities (pp. 407-440). San Diego: Academic Press.

Vaughn, S., \& Schumm, J. (1994). Middle school teachers planning for students with learning disabilities. Remedial \& Special Education, 15, 152-161.

Walker, H. M., Colvin, G., \& Ramsey, E. (1995). Antisocial behavior in school: Strategies and best practices. Pacific Grove, CA: Brooks/Cole.

Walker, H. M., \& Lamon, W. E. (1987). Social behavior standards and expectations of Australian and U.S. teacher groups. Journal of Special Education, 21, 56-82.

\section{PERMISSIONS AND COPYRIGHT}

All rights are reserved. No part of this publication may be reproduced, photocopied, faxed, stored in a retrieval system, or transmitted, in any form or by any means, electronic, mechanical, recording or otherwise, without the prior written permission of the publisher.
Back issues are available for sale. Reproduction requires permission and payment of fees. It is illegal and a violation of federal copyright law to reproduce this publication without permission. Direct all inquiries to the permissions editor. 


\title{
Excellence in Educating Gifted \& Talented Learners
}

\author{
Third Edition \\ Joyce Van Tassel-Baska
}

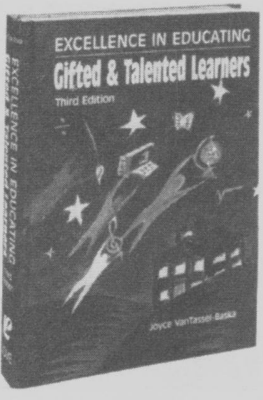

This unique book is brightly written and addresses the key issues and ideas in educating the gifted and talented population. You'll find it covers personality types and learning styles plus stages of giftedness from infancy to adulthood. It not only gives the characteristics and needs, but discusses grouping and acceleration and offers a comprehensive model of program development. Special attention is given to mathematics, science, social studies, and the humanities. This text translates the latest research into strategies and methods that work.

\section{Special Features}

- Interweaves the characteristics of the gifted with program development and curriculum

- Explores thinking skills and creativity

- Includes new ideas for grouping students

- Covers both cognitive and affective needs

- Packed with new ideas for curriculum modifications

9706/hardback/544 pages/\$58.00/ISBN: 0-89108-255-7

\section{EXCELLENCE IN EDUCATING \\ GIFTED \& TALENTED LEARNERS}

Please send me copies at $\$ 58.00$ per copy

Name

Address

Method of Payment

Check Enclosed Purchase Order Number (attach copy of PO)

Charge to: Visa MasterCard Card Number

Name on Card Expiration

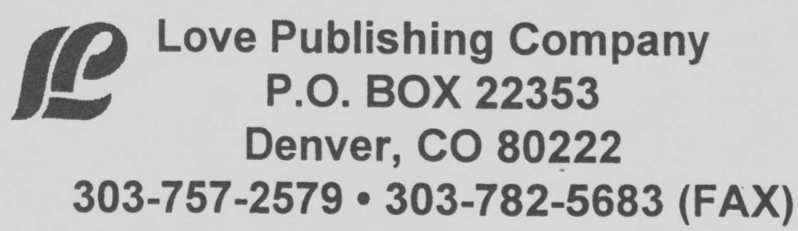




\section{Professional update}

\section{National Association of School Psychologists}

April 14-18, 1998

Annual Conference

Orlando, FL

Contact: National Association of School Psychologists 4340 East West Highway

Suite 402

Bethesda, MD 20814

\section{Learing Disabilites Association of America}

March 11-14, 1998

Hilton Hotel

Washington, DC

Contact: Learning Disabilities Association of America 4156 Library Rd

Pittsburgh, PA 15234

\section{Council for Exceptional Children}

April 15-19, 1998

Annual Conference

Minneapolis, MN

Contact: Council for Exceptional Children

1920 Association Drive

Reston, VA 22091 